\title{
Kinetics of Inhibition of Xanthine Oxidase by Lycium arabicum and its Protective Effect against Oxonate- Induced Hyperuricemia and Renal Dysfunction in Mice
}

\author{
Hayat Trabsa ${ }^{1 *}$, Abderrahmane Baghiani ${ }^{1}$, Naouel Boussoualim ${ }^{1}$, Imane \\ Krache $^{1}$, Seddik Khennouf ${ }^{2}$, Noureddine Charef ${ }^{1}$ and Lekhmici Arrar ${ }^{1}$ \\ ${ }^{1}$ Laboratory of Applied Biochemistry, ${ }^{2}$ Laboratory of Phytotherapy Applied to Chronic Diseases, Faculty of Nature and Life \\ Sciences, Univ. Setif, Setif 19000, Algeria \\ *For correspondence: Email: hayat.trab@yahoo.fr; Tel: +213560954133
}

\begin{abstract}
Purpose: To evaluate the in-vitro inhibition of xanthine oxidase (purified from bovine milk) by extracts of Lycium arabicum, as well as it is in vivo hypouricemic and renal protective effects.

Methods: Four extracts of Lycium arabicum, methanol (CrE), chloroform (ChE), ethyl acetate (EaE) and aqueous (AqE) extracts, were screened for their total phenolics and potential inhibitory effects on purified bovine milk xanthine oxidase (XO) activity by measuring the formation of uric acid or superoxide radical. The mode of inhibition was investigated and compared with the standard drugs, allopurinol, quercitin and catechin. To evaluate their hypouricemic effect, the extracts were administered to potassium oxonate-induced hyperuricemic mice at a dose of $50 \mathrm{mg} / \mathrm{kg}$ body weight.

Results: The results showed that EaE had the highest content of phenolic compounds and was the most potent inhibitor of uric acid formation $\left(I C_{50}=0.017 \pm 0.001 \mathrm{mg} / \mathrm{mL}\right)$ and formation of superoxide $\left(I C_{50}=0.035 \pm 0.001 \mathrm{mg} / \mathrm{ml}\right)$. Lineweaver-Burk analysis showed that CrE and EaE inhibited XO competitively, whereas the inhibitory activities exerted by ChE and AqE were of a mixed type. Intraperetoneal injection of $L$. arabicum extracts $(50 \mathrm{mg} / \mathrm{kg})$ elicited hypouricemic actions in hyperuricemic mice. Hyperuricemic mice presented a serum uric acid concentration of $4.71 \pm 0.29 \mathrm{mg} / \mathrm{L}$ but this was reduced to $1.78 \pm 0.11 \mathrm{mg} / \mathrm{L}$ by EaE, which was the most potent hyporuricemic extract.

Conclusion: L. arabicum fractions have a strong inhibitory effect on xanthine oxidase and and also have a significantly lowering effect on serum and liver creatinine and urea levels in hyperuricemic mice.
\end{abstract}

Keywords: Lycium arabicum, Uric acid, Creatinine, Superoxide, Phenolic compounds, Flavonoids, Hyperuricemia

\footnotetext{
Tropical Journal of Pharmaceutical Research is indexed by Science Citation Index (SciSearch), Scopus, International Pharmaceutical Abstract, Chemical Abstracts, Embase, Index Copernicus, EBSCO, African Index Medicus, JournalSeek, Journal Citation Reports/Science Edition, Directory of Open Access Journals (DOAJ), African Journal Online, Bioline International, Open-J-Gate and Pharmacy Abstracts
}

\section{INTRODUCTION}

Xanthine oxidoreductase $(X O R)$ is part of a group of enzymes known as molybdenum ironsulfur flavin hydroxylases. Animal XORs are homodimers with a molecular mass of about 300 $\mathrm{KDa}$. Each subunit contains a single peptide chain, which binds one molybdopterin cofactor (Mo-pt), two non identical 2Fe-2S centers, and one FAD cofactor. It exists in two interconvertible forms known as xanthine oxidase $(\mathrm{XO})$ and xanthine dehydrogenase (XDH) XOR is involved in the oxidation of hypoxanthine to xanthine and xanthine to urate [1]. The lack of uricase in humans results in plasma uric acid concentrations that are much higher than in most mammals. When these concentrations exceed the solubility limit of about $7 \mathrm{mg} / \mathrm{dL}$ 
(hyperuricimia) at physiological $\mathrm{pH}$, uric acid may nucleate to form crystals in tissues and joints [2]. These crystals can induce an acute inflammatory response, leading to the clinical presentation of acute gouty arthritis [3].

Standard management of acute gout consists of urate-lowering therapy. Allopurinol, a xanthine oxidase inhibitor, is the most commonly prescribed of these agents. However, a prolonged use of allopurinol leads to many of side effects e.g. hepatitis, nephropathy, allergic reaction and 6-mercaptopurine toxicity [4].

Therefore, there is urgent need to develop new XO inhibitors from natural sources. Lycium arabicum is a medicinal plant that grows wild in the mountains of Oures, Algeria. It belongs to Solanaceae family, used in traditional medicine to treat skin inflammation and rheumatism. The aim of this study was to evaluate the in vitro inhibition of xanthine oxidase as well as the in vivo hypouricimic effect of $L$. arabicum extracts in mice.

\section{EXPERIMENTAL}

\section{Materials}

The leaves of $L$. arabicum were obtained from N'Gaous, Batna, Algeria, at the end of March 2012 (between 11.00 - 14.00 h). The plant materials were identified and authenticated by Prof Oudjhih Bachir, a taxonomist at Department of Agronomy, Batna University, Batna, Algeria. A voucher specimen (I.A.B./950) was kept in the herbarium of the same department for future reference. Bovine milk was obtained from a local farm Batna, Algeria. All reagents were purchased from Sigma Chemicals, Fluka (Germany) and Prolab (Germany). The standard spectrophotometric diagnostic kits (uric acid, urea and creatinine) purchased from Spinreact (Spain).

Adult male mice (weighting 25 - $30 \mathrm{~g}$ ) were purchased from the Pasteur Institute of Algeria were kept under standardized conditions (21 - 24 ${ }^{\circ} \mathrm{C}$ and a $12 \mathrm{~h}$ light/dark cycle) and fed a normal laboratory diet. Animal experiments were performed in accordance with National Guidelines for the Use and Care of Laboratory Animals [5]. Ethical approval, for the animal experimentation, was obtained from Ethics Review Committee of Faculty of Exact Sciences and Nature and Life Sciences, Biskra University, Biskra, Algeria (ref no. 307/V.D.P.G.). The animals were transferred to the laboratory at least 1 week before the experiments.

\section{Extraction of phenolic compounds}

The extractions were carried out according to the method of Markham [6], Lycium arabicum powder was soaked in $85 \%$ aqueous-methanol with a ratio of plant material and extracting solvent of $1: 10 \mathrm{w} / \mathrm{v}$, under agitation overnight at 4 ${ }^{\circ} \mathrm{C}$. The extract was filtered on filter paper then on sintered glass to obtain the first filtrate. This procedure was repeated on the residue using 50 $\%$ aqueous-methanol under agitation for $4 \mathrm{~h}$ to obtain the last filtrate. The first and the last filtrates were combined then the methanol was removed under reduced pressure on a rotavapor (Germany, bÜchi461) below $45{ }^{\circ} \mathrm{C}$. The methanol extract was coded as CrE. A defined portion (30 \%) of total CrE volume was lyophilized and stored at $-20{ }^{\circ} \mathrm{C}$ until its use. CrE was subjected to fractionation using liquid-liquid extraction, it was successively extracted with different solvents of increasing polarity: hexane for defatting, chloroform for aglycone flavonoids extraction and ethyl acetate for glycoside flavonoids extraction. The obtained organic layer of each partition was evaporated under reduced pressure on a rotavapor below $45^{\circ} \mathrm{C}$ to dryness and to afford hexane, chloroform, ethyl acetate and aqueous fractions coded as HxE, ChE, EaE and $\mathrm{AqE}$, respectively. All of these fractions were stored at $-20^{\circ} \mathrm{C}$ prior to use.

\section{Determination of total phenolic content}

Total phenolic content was determined using Folin-Ciocalteu reagent [7]. Two hundred microliters of diluted sample were added to $1 \mathrm{~mL}$ of 1:10 (v/v) Folin-Ciocalteu reagent. After $4 \mathrm{~min}$, $800 \mathrm{~mL}$ of saturated sodium carbonate solution $(75 \mathrm{~g} / \mathrm{L})$ was added. After $1 \mathrm{~h}$ of incubation at room temperature $\left(25{ }^{\circ} \mathrm{C}\right)$, the absorbance at $765 \mathrm{~nm}$ was measured. Gallic acid (0 - 160 $\mu \mathrm{g} / \mathrm{mL}$ ) was used for calibration of standard curve. The results were expressed as microgram gallic acid equivalent ( $\mu \mathrm{g} \mathrm{GAE}) / \mathrm{mg}$ of extract.

\section{Purification of milk xanthine oxidase (XO)}

XO was purified from mammalian milk in the presence of $10 \mathrm{mM}$ of dithiothreitol by ammonium sulphate fractionation followed by affinity chromatography on heparin-agarose. XOR concentration was determined by UVvisible spectrum using an absorption coefficient of $36000 \mathrm{M}^{-1} \mathrm{~cm}^{-1}$ at $450 \mathrm{~nm}$. The purity of enzyme was assessed on protein/flavin ratio $\left(P F R=A_{280} / A_{450}\right)$ and sodium dodecyl sulfate polyacrylamide gel electrophoresis (SDS-PAGE) (10\%) [8]. 
Evaluation of inhibitory activity of XO formation of uric acid

The effect of $L$. arabicum extracts on $X O$ was examined spectrophotometrically at $295 \mathrm{~nm}$ by following the production of uric acid using an absorption coefficient of $9600 \mathrm{M}^{-1} \mathrm{~cm}^{-1}$ [9]. Different concentrations of tested compounds and extracts were added to and their effect on the generation of uric acid was used to calculate regression lines. The reaction was initiated by the addition of enzyme and inhibition was evaluated after $1 \mathrm{~min}$. The absorption increments at $295 \mathrm{~nm}$ indicating the formation of uric acid were measured at room temperature. Inhibition of $\mathrm{XO}$ was calculated Eq 1.

Inhibition $(\%)=\{(\mathrm{Ac} \mathrm{As}) / \mathrm{Ac}\} 100$

where Ac is XO activity without extract and AS is $X O$ activity with extract. The results are expressed as extract concentration that inhibited $50 \%$ of enzyme activity $\left(\mathrm{IC}_{50}\right)$.

\section{Evaluation of inhibitory activity of XO - formation of superoxide}

Effects of $L$. arabicum extracts on the generation of $\mathrm{O}_{2}$ were determined using the cytochrome $\mathrm{c}$ method [10] which is based on the ability of superoxide produced by xanthine/XO system to reduce cytochrome $c$. The reaction mixture contained xanthine $(100 \mu \mathrm{M})$ and cytochrome c $(25 \mu \mathrm{M})$ in air-saturated phosphate buffer (50 $\mathrm{mM}, \mathrm{pH}$ 7.4) supplemented with 0.1 mM EDTA. The reaction was started by the addition of the enzyme. Within $1 \mathrm{~min}$, reduced cytochrome c was calorimetrically determined at $550 \mathrm{~nm}$ against enzyme-free mixture using. The cytochrome c activity was calculated using an absorption coefficient of $21100 \mathrm{M}^{-1} \cdot \mathrm{cm}^{-1}$. The results, expressed as extract concentration that inhibited the reduction of half-amount of cytochrome c $\left(\mathrm{IC}_{50}\right)$.

\section{Determination of enzyme inhibition mechanism}

To determine the mode of inhibition by $L$. arabicum fractions [11], Lineweaver-Burk plot analysis was performed using Sigma Plot 12.0. The assay was carried out in the presence and absence of $L$. arabicum extracts with varying concentrations of xanthine $(10,20,40,6,80$, $100,120 \mu \mathrm{M})$ as the substrate, using the XO assay methodology. The mode of inhibition was compared with that of the positive control compounds: allopurinol, quercitin and catechin. The $\mathrm{XO}$ used was $0.02 \mathrm{U} / \mathrm{mL}$ to allow a more accurate determination of enzyme activity at low substrate concentrations. The Lineweaver-Burk transformed values were plotted to determine the mode of inhibition.

\section{Animal model of hyperuricemia}

The method of Mo et al [12], with slight modifications, was used. Potassium oxonate (PO) is a uricase inhibitor used to induce hyperuricemia in mice. $1 \mathrm{~h}$ before intraperitoneal injection of $L$. arabicum extracts $(50 \mathrm{mg} / \mathrm{kg})$ extracts, the mice were intraperitoneally injected with PO $(250 \mathrm{mg} / \mathrm{kg})$. Blood samples were then collected in heparinized tubes $1 \mathrm{~h}$ after the administration of $L$. arabicum extracts and allopurinol $(10 \mathrm{mg} / \mathrm{kg}$ ). Two control groups were used: normal group (without PO treatment) and $\mathrm{PO}$ groups (treated with $\mathrm{PO}$ only). The blood was centrifuged at $3500 \mathrm{rpm}$ for $5 \mathrm{~min}$ to obtain the serum. The serum was stored at $-20{ }^{\circ} \mathrm{C}$ until assayed. Livers were surgically excised from the mice that had been sacrificed by decapitation. The excised liver was rinsed in a saline buffer and was homogenized in an ice-cold $50 \mathrm{mM}$ potassium phosphate buffer, $\mathrm{pH}$ 7.8. The homogenate was centrifuged at $1500 \mathrm{~g}$ for 10 min at $4{ }^{\circ} \mathrm{C}$ and the pellet was discarded. The supernatant fraction was used to measure uric acid concentration.

\section{Assessment of renal function}

Blood and liver samples were prepared in the same way as for the uric acid measurements. For renal function assessment, urea and creatinine levels were measured using a semiautomatic Biochemistry Analyzer (Bechman) with standard spectrophotometric diagnostic kits purchased from Spinreact (Spain).

\section{Statistical analysis}

The results are expressed as mean \pm SD or SEM. Where applicable, the data were subjected to one-way analysis of variance (ANOVA), where the differences between extracts were determined by Tukey's multiple comparison test, Dunnett's and multiple comparison test for comparison between extracts and standards, using GraphPad program. $P \leq 0.05$ was regarded as significant.

\section{RESULTS}

\section{Total phenolic content}

The content of polyphenols in the extracts was in the following rank order: $\mathrm{EaE}>\mathrm{CrE}>\mathrm{ChE}>\mathrm{AqE}$ (Table 1). 
Table 1: Total polyphenols content of $L$. arabicum extracts

\begin{tabular}{ll}
\hline Extract & $\begin{array}{c}\text { Total phenols }(\boldsymbol{\mu g} \\
\text { AGE/mg) }\end{array}$ \\
\hline $\mathrm{CrE}$ & $276.16 \pm 3.71$ \\
$\mathrm{ChE}$ & $234.86 \pm 0.81$ \\
$\mathrm{EaE}$ & $278.55 \pm 2.02$ \\
$\mathrm{AqE}$ & $163.37 \pm 4.96$ \\
& \\
\hline Values are mean $\pm S D(n=3)$
\end{tabular}

\section{Milk xanthine oxidase (XO)}

The results of the freshly purified milk XOR from different species showed an ultraviolet/visible spectrum with three major peaks $(280,325,450$ $\mathrm{nm}$ ) with $\mathrm{A}_{280} / \mathrm{A}_{450}$ (protein to flavin ratio, PFR) of 5.15 indicating a high degree of purity, the specific activity of the purified enzyme was of $2055.05 \mathrm{nmol} / \mathrm{min} / \mathrm{mg}$ protein. Run on SDSPAGE, purified enzyme showed quite similar patterns with one major band of approximately $150 \mathrm{KDa}$.

\section{Inhibitory activity of XO}

All fractions of $L$. arabicum elicited a dosedependent inhibition of XO enzyme activity. The $I_{50}$ results showed that the highest activity was observed with the $\mathrm{EaE}(17.92 \pm 0.16 \mu \mathrm{g} / \mathrm{mL})$ followed by $\mathrm{ChE}(39.11 \pm 0.28 \mu \mathrm{g} / \mathrm{mL})$, AqE $(63.77 \pm 0.16 \mu \mathrm{g} / \mathrm{mL})$ and $\mathrm{CrE}(85.38 \pm 6.36$ $\mu \mathrm{g} / \mathrm{ml}$ ) (Figure 1). The standard drug, allopurinol, had an $\mathrm{IC}_{50}$ of $8.57 \pm 0.30 \mu \mathrm{g} / \mathrm{mL}$.

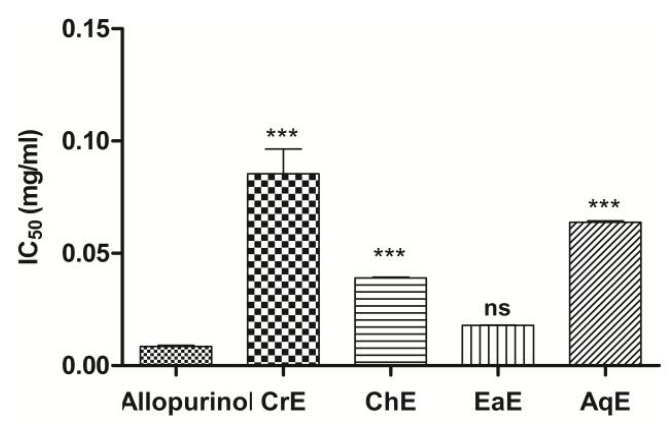

Figure 1: Inhibition of uric acid production by $L$. arabicum extracts. Values are mean \pm SD $(n=3) ;{ }^{* * *} p$ $\leq 0.001, n s=$ not significance, compared to allopurinol

The results shown in Figure 2 indicate that EaE presents the most potent scavenging effect of O2.- with an $\mathrm{IC}_{50}$ of $0.035 \pm 0.001 \mathrm{mg} / \mathrm{mL}$, which is approximately 2-fold higher than that of AqE $(0.062 \pm 0.001 \mathrm{mg} / \mathrm{mL})$. On the other hand, ChE and $\mathrm{CrE}$ presented approximately the same scavenger activity $(0.240 \pm 0.008$ and $0.282 \pm$ $0.012 \mathrm{mg} / \mathrm{mL}$, respectively).

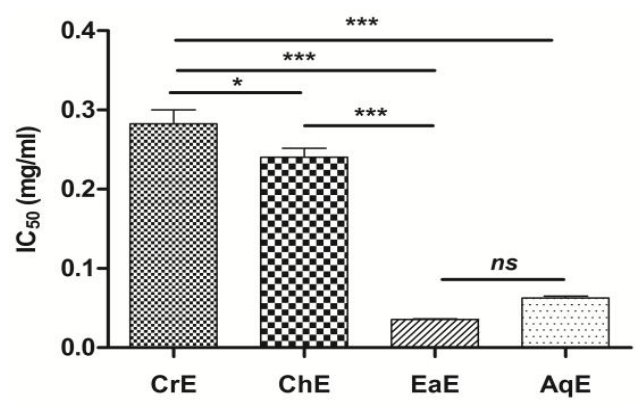

Figure 2: Effect of $L$. arabicum on the formation of $\mathrm{O}_{2}{ }^{--}$ . Values are mean $\pm \mathrm{SD}(\mathrm{n}=3) ;{ }^{*} p \leq 0.05,{ }^{* * *} p \leq$ 0.001 , and $n s=$ not significance

\section{Enzyme inhibition mechanism}

The data indicates that the $\mathrm{EaE}(18 \mu \mathrm{g} / \mathrm{ml})$, which is a potent inhibitor of xanthine oxidase, showed a competitive inhibition pattern (Figure $3)$, as did the $\operatorname{CrE}(93 \mu \mathrm{g} / \mathrm{mL})$. The same type of inhibition was found in the case allopurinol (8 $\mu \mathrm{g} / \mathrm{mL}$ ) (Figure 4).

However, ChE and AqE showed mixed-type of inhibition (Figure 5). Mixed inhibition was similarly observed for quercitin $(50 \mu \mathrm{g} / \mathrm{mL})$. Our results showed that glycosidic flavonoids (EaE) of $L$. arabicum present the highest inhibition of $\mathrm{XO}$ and in a competitive type and the nonglucosidic flavonoids (ChE) showed a mixed inhibition.

The results confirmed that catechin and quercitin showed a noncompetitive and mixed inhibition, respectively, at a dose of $50 \mu \mathrm{g} / \mathrm{ml}$ (Figure 6).

\section{In vivo hypouricemic effect of $L$. arabicum extracts}

Mice treated with $250 \mathrm{mg} / \mathrm{kg}$ potassium oxonate exhibited a significant elevation of serum uric acid levels in comparison to normal-vehicle group (Table 2). The administration of $L$. arabicum extracts significantly decreased serum and liver uric acid levels. However, AqE present a strong in vitro XO inhibitory effect but not a strong hypouricemic activity.

The results showed that the administration of $\mathrm{PO}$ to the increase levels of urea and creatinine in serum and liver (Table 3 ). The results showed that the administration of $L$. arabicum extracts and allopurinol decrease urea and creatinine levels. 

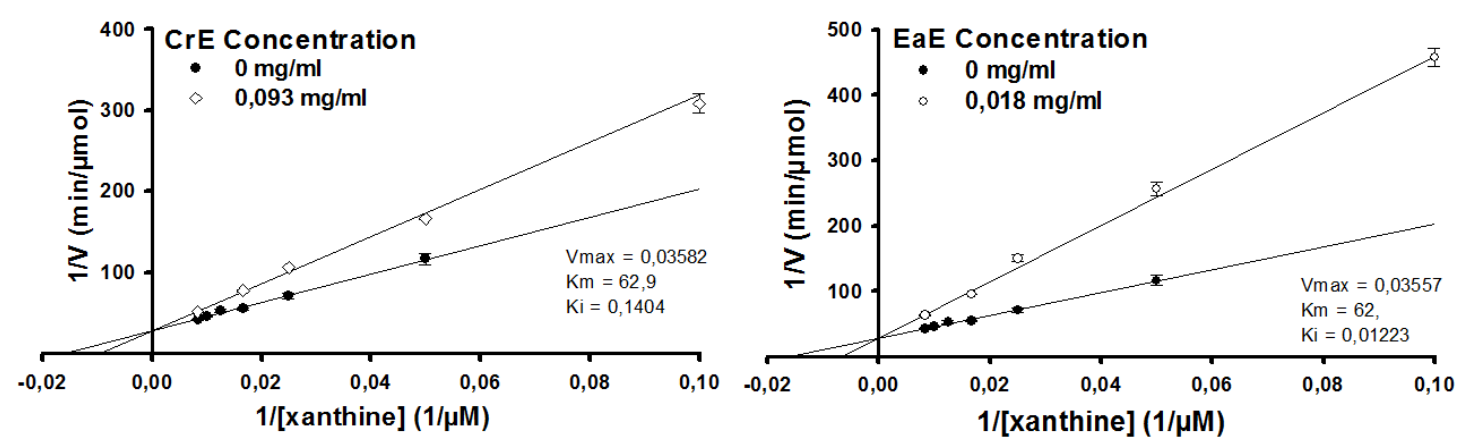

Figure 3: Lineweaver-Burk plot of inhibition of $\mathrm{XO}$ by $\mathrm{CrE}$ and EaE of L. arabicum. Values are mean $\pm \mathrm{SD}(n=3)$

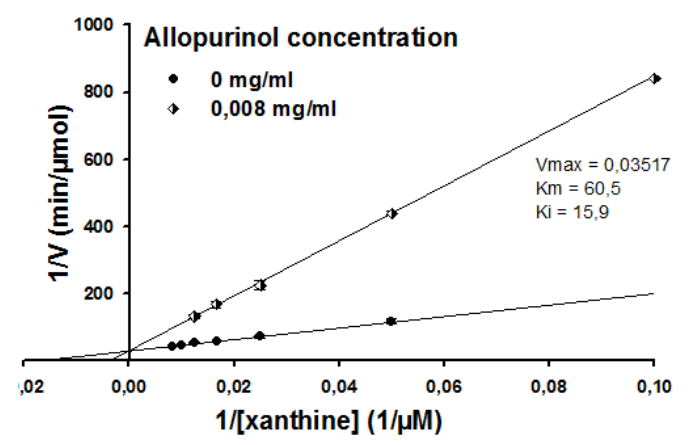

Figure 4: Lineweaver-Burk plot of inhibition of XO by allopurinol. Values are mean $\pm S D(n=3)$
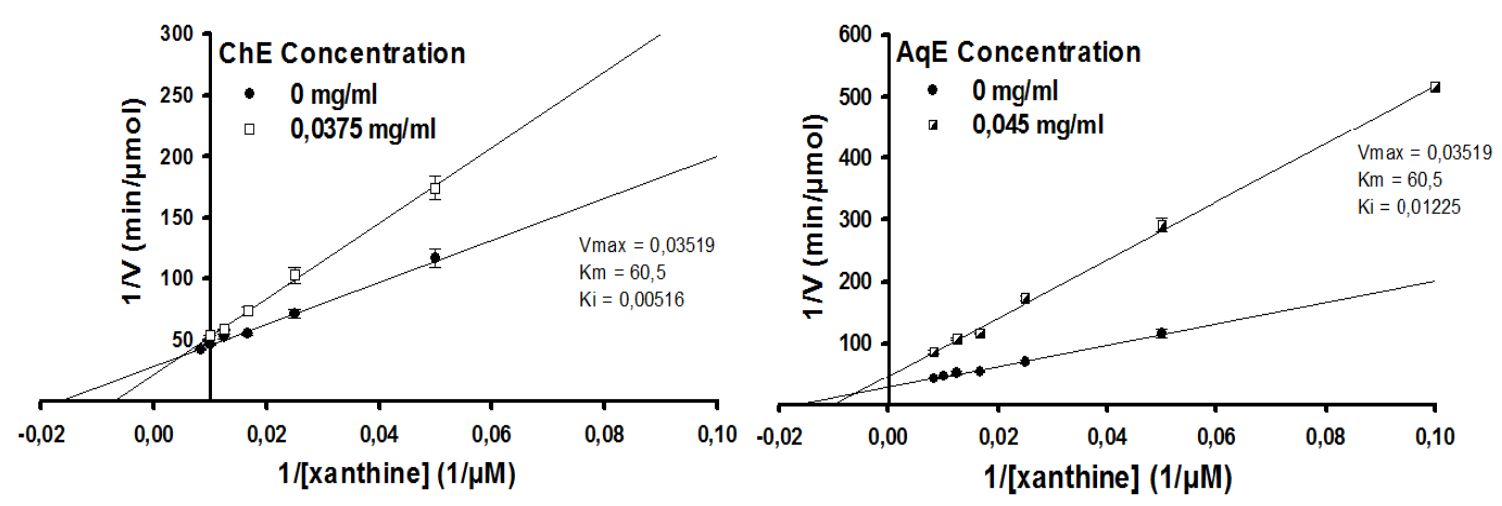

Figure 5: Lineweaver-Burk plot of mixed inhibition of $\mathrm{XO}$ by $\mathrm{ChE}$ and AqE. Values were expressed as mean \pm $\operatorname{SD}(n=3)$
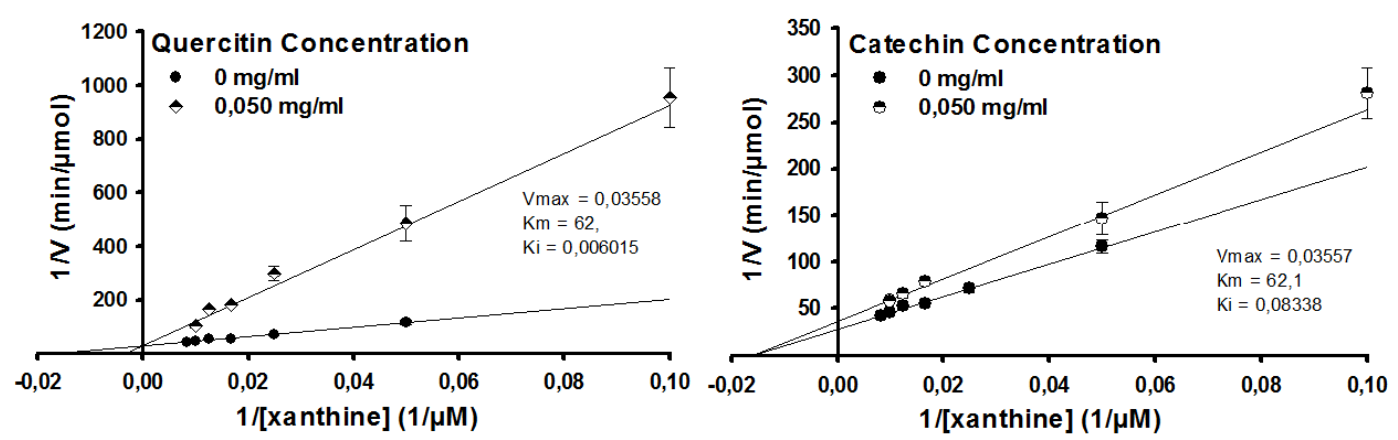

Figure 6: Lineweaver-Burk plot of inhibition of $X O$ by quercetin and catechin. Values are mean $\pm S D(n=3)$ 
Table 2: Serum and liver uric acid levels $(\mathrm{mg} / \mathrm{L})$ in normal hyperuricemic mice and treated with allopurinol and extracts

\begin{tabular}{lcc}
\hline Group & Serum & Liver \\
\hline Normal & $1.55 \pm 0.12$ & $4.18 \pm 0.21$ \\
PO & $4.71 \pm 0.29$ & $10.35 \pm 0.83$ \\
PO+allopurinol & $1.89 \pm 0.10^{* * *}$ & $1.54 \pm 0.13^{\star * *}$ \\
PO+CrE & $1.92 \pm 0.09^{\star * *}$ & $4.16 \pm 0.39^{\star * *}$ \\
PO+ChE & $1.88 \pm 0.16^{* * *}$ & $2.70 \pm 0.20^{\star * *}$ \\
PO+EaE & $1.78 \pm 0.11^{* * *}$ & $1.74 \pm 0.18^{\star * *}$ \\
PO+AqE & $3.24 \pm 0.21^{* * *}$ & $5.88 \pm 0.38^{\star * *}$ \\
\hline
\end{tabular}

Normal; Non treated group, PO; hyperuricemic mice, PO+allopurinol; hyperuricemic mice treated with allopurinol $(10 \mathrm{mg} / \mathrm{kg}), P O+C r E ;$ hyperuricemic mice treated with CrE (50 mg/kg), PO+ChE; hyperuricemic mice treated with ChE (50 mg/kg), PO+EaE; hyperuricemic mice treated with EaE (50 mg/kg) and PO+AqE; hyperuricemic mice treated with AqE (50 mg/kg). Values are mean \pm SEM $(n=10)$, compared with $P O ;{ }^{* * *}: p \leq 0.001$

Table 3: Urea ( $\mathrm{g} / \mathrm{L})$ and creatinine $(\mathrm{mg} / \mathrm{L})$ levels in normal and hyperuricemic mice treated with allopurinol and extracts

\begin{tabular}{lcccc}
\hline \multirow{2}{*}{ Group } & \multicolumn{2}{c}{ Serum } & \multicolumn{2}{c}{ Liver } \\
\cline { 2 - 5 } & Urea & Creatinine & Urea & Creatinine \\
\hline Normal & $0.012 \pm 0.002$ & $1.000 \pm 0.002$ & $0.100 \pm 0.012$ & $1.571 \pm 0.202$ \\
PO & $0.070 \pm 0.004$ & $3.570 \pm 0.012$ & $0.178 \pm 0.002$ & $4.375 \pm 0.263$ \\
PO+Allopurinol & $0.014 \pm 0.002^{* * *}$ & $1.571 \pm 0.202^{* * *}$ & $0.138 \pm 0.014^{n s}$ & $2.800 \pm 0.200^{* * *}$ \\
PO+CrE & $0.044 \pm 0.002^{* * *}$ & $1.800 \pm 0.200^{* * *}$ & $0.133 \pm 0.011^{n s}$ & $3.000 \pm 0.189^{* * *}$ \\
PO+ChE & $0.017 \pm 0.001^{* * *}$ & $1.014 \pm 0.014^{* * *}$ & $0.104 \pm 0.011^{*}$ & $3.286 \pm 0.285^{* *}$ \\
PO+EaE & $0.016 \pm 0.002^{* * *}$ & $1.500 \pm 0.223^{* * *}$ & $0.117 \pm 0.015^{*}$ & $2.714 \pm 0.184^{* * *}$ \\
PO+AqE & $0.057 \pm 0.002^{*}$ & $2.333 \pm 0.210^{* * *}$ & $0.122 \pm 0.020^{n s}$ & $2.571 \pm 0.202^{* * *}$ \\
\hline
\end{tabular}

Values were expressed as mean \pm SEM $(n=10)$, compared with hyperuricemic group $(P O) ;{ }^{*} p \leq 0.05,{ }^{* *} p \leq 0.01$, ${ }^{* * *} p \leq 0.001, n s=$ non-significant

\section{DISCUSSION}

Phenolic compounds including phenolic acids and flavonoids are known to possess biological and pharmacological activities, including antioxidative, anti-bacterial, anti-viral and antimutagenic activities. Flavonoids are also known to be potent inhibitors of several enzymes, including xanthine oxidase, cyclooxygenase, 5lipooxigenase and phosphoinositide 3-kinase [13].

The most potent $\mathrm{XO}$ inhibitor observed was EaE which was 2-folds lower than allopurinol, its activity could be explained by its high polyphenolic content. However, the $\mathrm{IC}_{50}$ of ECh is lower than that of $\mathrm{CrE}$, the total polyphenols contents of $\mathrm{CrE}$ was found higher than that of $\mathrm{ChE}$. Our results showed that the XO inhibition could be linked not only on the polyphenols and flavonoids contents of the extract, but also to the nature (structure) of these compounds.

The scavenging effect of free radicals by various constituents of plants may be due to phenolic acids and flavonoids [9]. The different extracts of $L$. arabicum inhibitory effects on $\mathrm{XO}$, which makes it difficult to know, in the test of Cyt-c, if these extracts have a scavenger effect on $\mathrm{O}^{\circ}{ }^{-}$ or an inhibitory effect on the enzyme. The $\mathrm{IC}_{50}$ of
$\mathrm{EaE}, \mathrm{CrE}$ and $\mathrm{ChE}$ for the production of uric acid from the oxidation of xanthine by $\mathrm{XO}$ is nearly 2 , 3 and 6 times lower than that inhibiting the reduction of Cyt c, respectively. The AqE present nearly the same $\mathrm{IC}_{50}$.

Both allopurinol and oxypurinol, (isosteres of hypoxanthine and xanthine, respectively), inhibit xanthine oxidase, thereby limiting the biosynthesis of uric acid and decreasing its serum level and urine excretion and promoting the renal clearance of hypoxanthine and xanthine. Allopurinol, a competitive inhibitor, is a substrate for xanthine oxidase, which strongly binds at the active site, with concomitant reduction of the molybdenum site. The binding of oxypurinol to the reduced molybdenum site of the enzyme has been shown to be reversible and released after re-oxidation of the enzyme. Although the inhibitor binds very tightly to the enzyme, the inhibition is time-dependent and, therefore, it takes some time to inhibit the enzyme completely [14].

Tea catechins have been shown to exhibit moderate $\mathrm{XO}$ inhibition at low concentrations [15], and to inhibit XO non-competitively [16]. Takahama et al (2011) reported that the quercetin-dependent inhibition of XO activity was a mixed-type namely, competitive/non- 
competitive inhibition [17]. Our results confirm these findings, where catechin and quercitin showed a noncompetitive and mixed inhibition, respectively, at a dose of $50 \mu \mathrm{g} / \mathrm{mL}$.

Potassium oxonate, a selective uricase inhibitor, blocks the effect of hepatic uricase and produces hyper-uricemia [12]. The AqE exhibited a strong in vitro XO inhibitory effect but not a strong hypouricemic activity. It is possible that differences in the structure, absorption and metabolism of various tested extracts may lead to the formation of metabolites with different $\mathrm{XO}$ inhibitory activities. Renal failure is the cessation of renal function and it can be acute or chronic. In acute renal failure there is rapid loss of renal function within hours or days, although the condition is potentially reversible and normal renal function can be regained. The deterioration is sudden, with increases in the concentrations of urea and creatinine [18].

Oxonate-treated mice consistently produced increased plasma creatinine and urea levels which indicates renal dysfunction [19]. Studies showed that allopurinol therapy significantly decreases serum uric acid levels in hyperuricemic patients with mild to moderate chronic kidney disease. Its use is safe and helps preserve kidney function during 12 months of therapy [20]. Which explain the normal level of creatinine and urea in hyperuricemic mice treated with allopurinol $(10 \mathrm{mg} / \mathrm{Kg})$. L. arabicum extracts decrease significantly urea and creatinine serum levels, EaE, the best hypouricemic extract, presented a protective effect higher than that of allopurinol. However, AqE did not show a strong hypouricemic activity but it has a strong protective effect by decreasing of urea and creatinine levels.

\section{CONCLUSION}

L. arabicum extracts have significant inhibition effect on $\mathrm{XO}$ activity in vitro as well as a significant hypouricemic effect in huperuricemic mice. Inconsistencies between the in vitro and in vivo data may be due to differences in the bioavailability of extracts and their extensive metabolism in mice. These results suggest that L. arabicum may be helpful in preventing or slowing the progress of several diseases that are related to $\mathrm{XO}$.

\section{ACKNOWLEDGEMENT}

This work was supported by the Algerian Ministry of Higher Education and Scientific Research
(MESRS) and by Algerian Agency for the Development of Research in Health (ANDRS).

\section{REFERENCES}

1. Nishino $T$, Okamoto $K$, Eger BT, Pai EF, Nishino $T$. Mammalian xanthine oxidoreductase mechanism of transition from xanthine dehydrogenase to xanthine oxidase. FEBS J. 2008; 275: 3278-3289.

2. Sherman MR, Saifer MGP, Perez-Ruiz F. PEG-uricase in the management of treatment-resistant gout and hyperuricemia. Adv Drug Deliv Rev. 2008; 60: 59-68.

3. Busso $N$, So A. Mechanisms of inflammation in gout. Arthritis Res Ther. 2010; 206(12):1-8.

4. Fravel MA, Ernst ME. Management of Gout in the Older Adult. Am J Geriatr Pharmacother. 2011; 9(15): 271285.

5. Gay WI. Methods of animal experimentation (Vol-I). New York: Academic Press; 1965 ; pp 32-191.

6. Markham KR. Techniques of flavonoid identification. London: Academic Press; 1982; pp 1-113.

7. Li HB, Cheng KW, Wong CC, Fan KW, Chen F, Jiang $Y$. Evaluation of antioxidant capacity and total phenolic content of different fractions of selected microalgae. Food Chem. 2007; 102: 771-776.

8. Baghiani A, Harrison R, Benboubetra M. Purification and partial characterisation of camel milk xanthine oxidoreductase. Arch Physiol Biochem. 2003; 111(5): 407-414.

9. Boumerfeg S, Baghiani A, Messaoudi D, Khennouf S, Arrar L. Antioxidant properties and xanthine oxidase inhibitory effects of Tamus communis L. root extracts. Phytother Res. 2009; 23: 283-288.

10. Selloum L, Reichl S, Müller M, Sebihi L, Arnhold J. Effects of flavonols on the generation of superoxide anion radicals by xanthine oxidase and stimulated neutrophils. Arch Biochem Biophys. 2001; 395(1): 4956.

11. Yu Z, Fong WP, Cheng HKC. The dual actions of morin (3, 5, 7, 2, 4-pentahydroxyflavone) as a hypouricemic agent: uricosuric effect and xanthine oxidase inhibitory activity. J Pharmacol Exp Ther. 2006; 316(1): 169-175.

12. Mo S, Zhou F, Lv Y, Hu Q, Zhang D, Kong $L$. Hypouricemic action of selected flavonoids in mice: structure-activity relationships. Biol Pharm Bull. 2007; 30(8): 1551-1556.

13. Lin CH, Chen CS, Chen CT, Liang YC, Lin JK. Molecular modeling of flavonoids that inhibits xanthine oxidase. Biochem Biophys Res Commun. 2002; 294: 167-172.

14. Borges F, Fernandes E, Roleir F. Progress towards the discovery of xanthine oxidase inhibitors. Curr Med Chem. 2002; 9: 195-217.

15. Özyürek M, Bektaşoğlu B, Güclü K, Apak R. Measurement of xanthine oxidase inhibition activity of phenolics and flavonoids with a modified cupric reducing antioxidant capacity (CUPRAC) method. Anal Chim Acta. 2009; 636: 42-50.

Trop J Pharm Res, February 2015; 14(2): 255 
16. Berboucha $M$, Ayouni $K$, Atmani D, Atmani $D$, Benboubetra M. Kinetic study on the inhibition of xanthine oxidase by extracts from two selected algerian plants traditionally used for the treatment of inflammatory diseases. J Med Food. 2009; 13(4): 1-9.

17. Takahama U, Koga Y, Hirota S, Yamauchi R, Inhibition of xanthine oxidase activity by an oxathiolanone derivative of quercetin. Food Chem. 2011; 126: 18081811.
18. Nessar A, Dawson M, Smith C, Wood D. Biology od disease. UK: Taylor and Franics 2007; 204-208.

19. Li JM, Zhang $X$, Wang $X$, Xie YC, Kong LD. Protective effects of cortex fraxini coumarines against oxonateinduced hyperuricemia and renal dysfunction in mice. Eur J Pharmacol. 2011; 666: 196-204.

20. Siu YP, Leung KT, Tong MKH, Kwan TH. Use of allopurinol in slowing the progression of renal disease through its ability to lower serum uric acid level. Am J Kidney Dis. 2006; 47 (1): 51-59. 